Article

\title{
Hydrotreating of Methyl Esters to Produce Green Diesel over Co- and Ni-Containing Zr-SBA-15 Catalysts
}

\author{
Cristina Ochoa-Hernández ${ }^{1,+}(\mathbb{D})$, Juan M. Coronado ${ }^{1, \ddagger(D)}$ and David P. Serrano ${ }^{1,2, *}$ \\ 1 Thermochemical Processes Unit, IMDEA Energy Institute, Móstoles, E28935 Madrid, Spain; \\ ochoa@mpi-muelheim.mpg.de (C.O.-H.); jm.coronado@csic.es (J.M.C.) \\ 2 Chemical and Environmental Engineering Group, ESCET, Rey Juan Carlos University, Móstoles, \\ E28933 Madrid, Spain \\ * Correspondence: david.serrano@imdea.org \\ † Current address: Department of Heterogeneous Catalysis, Max-Planck-Institut für Kohlenforschung, \\ D45470 Mülheim an der Ruhr, Germany. \\ $\ddagger$ Current address: Instituto de Catálisis y Petroleoquímica-CSIC, c/Marie Curie 2, Cantoblanco, \\ E28049 Madrid, Spain.
}

Received: 13 December 2019; Accepted: 1 February 2020; Published: 5 February 2020

\begin{abstract}
This work explores the performance of Zr-SBA-15 as a support for the conversion of methyl esters into green diesel. Thereby, a series of SBA-15 samples incorporating different amounts of $\mathrm{Zr}$ into the walls have been synthesized and impregnated with $\mathrm{Ni}$ and $\mathrm{Co}$ as hydrogenating species. All materials have been characterized, pelletized and tested in the hydrotreating of methyl esters using a fixed-bed tubular reactor at $300{ }^{\circ} \mathrm{C}, 30$ bar of $\mathrm{H}_{2}$ and a continuous flow of $0.1 \mathrm{~mL} / \mathrm{min}$ for $6 \mathrm{~h}$. $\mathrm{Co}$ and $\mathrm{Ni}$ phases are present both over the surface and within the pores of the support. Interactions between the metals and the $\mathrm{Zr}$ species are more pronounced for Co-containing samples, leading to smaller Co particles at low Si/Zr ratios. Materials having higher Zr contents resulted in more methyl ester conversion, although an adequate metal-support combination was required to promote the hydrodeoxygenation (HDO) route. Co/Zr-SBA-15 materials exhibited more conversion ( $>90 \%$ ) and higher yields of $C_{11}-C_{20}$ hydrocarbons $(>60 \%)$ than their Ni-based counterpart catalysts. Specifically, Co/Zr-SBA-15(17) sample showed remarkable behavior, favoring the HDO pathway (n- $\mathrm{C}_{18} /\left(\mathrm{n}-\mathrm{C}_{18}+\right.$ $\left.\left.n-C_{17}\right)>0.5\right)$, while keeping the methyl esters' conversion close to $100 \%$ along the time on stream. These results evidence a synergistic effect between Co and Zr.
\end{abstract}

Keywords: hydrotreating; hydrodeoxygenation; HDO; green diesel; vegetable oils; mesoporous materials; Zr-SBA-15; acidity

\section{Introduction}

Vegetable oils are one of the most interesting resources for the production of biofuels. Although their direct use in internal combustion engines is possible, their low volatility and high viscosity cause problems in the stages of pumping, atomization and mixing with the oxidizer, leading to the formation of carbonaceous deposits. In addition, the presence of significant oxygen content makes them have a lower heating value than their fossil oil counterparts [1,2]. The main transformation processes for converting vegetable oils into liquid biofuels for transportation are transesterification, catalytic cracking and hydrotreating.

Biodiesel is a mixture of esters produced by transesterification of vegetable oils in the presence of a catalyst and an alcohol (usually methanol). In addition, glycerol is formed as co-product. Biodiesel has been traditionally produced over basic homogenous catalysts, such as $\mathrm{NaOH}$ and $\mathrm{KOH}$. On the 
other hand, heterogeneous catalysts, such as metal oxides $(\mathrm{MgO}, \mathrm{CaO}, \mathrm{ZnO})[3]$, zeolites [3,4], periodic mesoporous organosilica [5,6] and mesoporous silica functionalized sulfonic acids [7], have been also investigated due to their advantages, such as easy separation and recycling. Biodiesel has similar properties to diesel from fossil resources in terms of density and cetane number. However, it has a higher viscosity than conventional diesel, which generates the formation of carbon deposits in the engine injectors. On the other hand, its greater corrosive character can damage the rubber or other components of both an engine and its feeding system. For these reasons, its use in transportation is limited, usually to being mixed with conventional diesel $[8,9]$.

The conversion of vegetable oils into hydrocarbons by catalytic cracking processes is normally carried out at atmospheric pressure, $450-600{ }^{\circ} \mathrm{C}$, in an inert atmosphere and in the presence of a heterogeneous acid catalyst such as ZSM-5 [10]. The liquid product so obtained contains linear and cyclic paraffins, olefins, aromatics, aldehydes, ketones, carboxylic acids and water. In addition, hydrogen and coke are also formed in the process. Catalytic cracking of vegetable oils seems to be a suitable choice for the production of gasoline range hydrocarbons and light olefins, which could be employed as fuels or raw materials for the petrochemical industry. The development of catalysts which are active, selective and have high deactivation resistance has motivated a large number of investigations in this field [11-16].

Hydrotreating is considered a promising alternative for the transformation of vegetable oils, since it is able to produce hydrocarbons in the diesel range with very similar properties to petroleum derivatives, and therefore, suitable for diesel engines. The final fuel obtained through this process is called "green diesel", HVO (hydrotreated vegetable oil) or hydro-biodiesel in order to distinguish it from biodiesel. This transformation requires high pressure hydrogen, mild temperatures and a supported metal catalyst. It can take place via hydrodeoxygenation (HDO) and/or decarbonylation/decarboxylation (HDC) reactions [17]. The HDO route leads to the removal of oxygen in form of water through several stages, including the formation of intermediates such as aldehydes and alcohols. Thus, linear paraffins are formed with same number of carbon atoms as the starting molecules (free fatty acids). The occurrence of HDC reactions produces n-alkanes with one carbon atom less than their corresponding fatty acids, releasing one molecule of $\mathrm{CO}_{2}$ or $\mathrm{CO}$ each time [18]. Therefore, HDO route is preferred over HDC from the point of view of carbon atom economy.

Hydrotreatment processes have been widely used in refineries for the removal of compounds containing sulfur, nitrogen, metals and oxygen in heavy vacuum gas oil. Typically, NiMo/CoMo sulfide catalysts, supported on alumina, are employed at $300-600{ }^{\circ} \mathrm{C}$ with $35-170$ bar of hydrogen pressure $[1,19]$. These types of catalytic systems have been generally applied to the hydrodeoxygenation of vegetable oils. However, these materials present a very significant limitation, since the addition of hydrogen sulfide, carbonyl disulfide or dimethyl disulfide is required to keep the catalysts in their active forms. Likewise, these types of catalysts are negatively affected by the presence of water, generated in significant amounts during the HDO process. In addition to sulfur materials supported on alumina, the usage of catalysts based on noble metals, especially $\mathrm{Pd}$ and $\mathrm{Pt}$, has been investigated in the deoxygenation of lipids and their derivatives [20-22]. However, one of the main disadvantages of using these metals is their high cost. On the other hand, the support employed to host the active phase also plays a very important role in the conversion of triglycerides. In this sense, different supports such as Al-SBA-15 [23], Al-MCM-41 [24], silicoaluminophosphates (SAPO) [25,26] and different zeolites have been studied [27,28]. Thus, Wang et al. compared various types of supports (SAPO-11, ZSM-5, ZSM-22, ZSM-23, Beta) impregnated with nickel and found the Ni/SAPO-11 system to be the best one [26]. Likewise, in a previous work, we reported the good performance of catalysts based on $\mathrm{Ni}$ and $\mathrm{Co}$ deposited over ordered mesoporous SBA-15 and Al-SBA-15 in the methyl oleate hydrodeoxygenation, showing the benefits of using bifunctional systems (having both metallic and acidic sites) for this reaction [29].

SBA-15 is a silica-based ordered mesoporous material, which is typically synthesized in the presence of block polymer surfactants. Although it is formed by amorphous silica, the mesopores 
show a highly ordered arrangement according to a hexagonal unit cell. Some microporosity is also present in SBA-15 sample connecting the mesopores transversally. Moreover, it exhibits a relatively high thermal stability as a consequence of the large thickness of the pore walls. The addition of $\mathrm{Al}$ or $\mathrm{Zr}$ species provides this material with acidic properties (Al-SBA-15 or Zr-SBA-15), although it leads, usually, to samples with high structural distortion.

Due to their singular properties, both SBA-15 and Al-SBA-15 have been widely investigated to disperse a large variety of catalytic active phases. This is the case when supporting a number of metals, such as $\mathrm{Ni}, \mathrm{Co}, \mathrm{Fe}, \mathrm{Pt}, \mathrm{Pd}, \mathrm{Ru}, \mathrm{Cu}$ and $\mathrm{Mo}$ to obtain catalysts with hydrodeoxygenation properties that have been applied in the hydrotreating of vegetable oils derived compounds [23,30-33]. On the other hand, different works have reported the benefits of incorporating $\mathrm{Zr}$ species into metal-containing SBA-15 in order to get a bifunctional catalyst with hydrogenating and acidic properties. Thus, Zr-containing SBA-15 has been employed as an effective support for Co to prepare Fisher-Tropsch catalysts $[34,35]$. In the same way, hydrodesulfurization catalysts, showing enhanced activity, have been prepared by supporting Mo, CoMo and NiMo phases on Zr-SBA-15 [36-38]. According to these works, the presence of $\mathrm{Zr}$ on the SBA-15 material provides a tunable acidity and increases the dispersion and reduction degree of the metal phases, which in turn provokes an improvement of the catalytic properties. However, in spite of the high potential of this system, Zr-containing SBA-15 has not been almost investigated in hydrodeoxygenation reactions.

Therefore, the current paper explores the interest of using Zr-SBA-15 as a support for the conversion of vegetable-oil-derived compounds, favoring the HDO pathway over the HDC route. Thus, Zr-SBA-15 samples were prepared with different $\mathrm{Si} / \mathrm{Zr}$ ratios, loaded with $\mathrm{Ni}$ and $\mathrm{Co}$ species and investigated as catalysts in the hydrotreating of methyl esters.

\section{Results and Discussion}

Characterization and catalytic results are presented and discussed in this section. Catalysts are named M/Zr-SBA-15(x), where M corresponds to Ni or Co and $x$ to the Si/Zr molar ratio. Details about the synthesis of catalysts, characterization techniques and reaction conditions are explained in Section 3: Materials and Methods.

\subsection{Catalyst Characterization Results}

Structural and surface characterizations of the M/Zr-SBA-15(x) catalysts were performed using different techniques so as to determine their main physicochemical properties. Table 1 summarizes the results of the elemental analyses carried out by inductively coupled plasma optical emission spectrometry (ICP-OES) for the Zr-SBA-15 supports, showing that the Si/Zr ratios are fully consistent with the nominal content. Similarly, metal loadings are also very close to the target of $5 \mathrm{wt} . \%$, particularly for Ni-based catalysts, while slight variations were observed for Co-based materials with values from 5.3 to $4.5 \mathrm{wt} . \%$.

The mesostructures of these materials were investigated by low-angle X-ray diffraction (XRD); the results are shown in Figure 1a. In the case of the parent Zr-SBA-15, three reflections could be observed in all cases. They are associated with the planes (100), (110) and (200) of the 2D hexagonal porous network with p6mm symmetry. These features appear slightly better resolved for the sample with $\mathrm{Si} / \mathrm{Zr}=88$. This is consistent with previous studies that observed some lowering of the mesoscopic order with increasing Zr content [39], although in the present case just minor differences are appreciated. Besides, a shift to lower angle of the (100) reflection with decreasing the Si/Zr ratio was observed. This implies larger unit cells and thinner walls for the mesostructured materials with higher $\mathrm{Zr}$ contents. This could be related to the increasing contribution of larger $\mathrm{Zr}-\mathrm{O}$ bonds with respect to Si-O bonds, in analogy with it has been proposed for explaining a similar behavior in Al-SBA-15 [40]. Incorporation of either $\mathrm{Co}$ or Ni does not modify the mesostructured, since the low angle reflections remain sharply defined. Nevertheless, a slight displacement to lower angle of the main peak with regard to that of the 
support can be appreciated for the catalyst based on Zr-SBA-15 (88), and especially for that containing $\mathrm{Ni}$. This fact suggests a further widening of the walls of the mesophase upon metal deposition.

Table 1. Physicochemical parameters of the synthesized catalysts expressed per gram of support ( $g_{\text {sup }}$ ).

\begin{tabular}{|c|c|c|c|c|c|c|c|}
\hline Sample & $\begin{array}{c}\text { Metal } \\
\text { Loading }{ }^{1} \\
\text { (wt.\%) }\end{array}$ & $\mathrm{Si} / \mathrm{Zr}^{1}$ & $\begin{array}{c}\mathrm{S}_{\mathrm{BET}}{ }^{2} \\
\left(\mathrm{~m}^{2} / \mathrm{g}_{\text {sup }}\right)\end{array}$ & $\begin{array}{l}\mathrm{Dp}{ }^{3} \\
(\mathrm{~nm})\end{array}$ & $\begin{array}{c}V_{T}{ }^{4} \\
\left(\mathrm{~cm}^{3} / g_{\text {sup }}\right)\end{array}$ & $\begin{array}{c}\text { Acidity } \\
\text { (meq } \\
\mathrm{NH}_{3} / \mathrm{g}_{\text {sup }} \text { ) }\end{array}$ & $\begin{array}{c}\mathrm{T}_{\max }{ }^{6} \\
\left({ }^{\circ} \mathrm{C}\right)\end{array}$ \\
\hline Zr-SBA-15(17) & - & 17 & 701 & 12.4 & 1.60 & 0.244 & 250 \\
\hline Ni/Zr-SBA-15(17) & 5.1 & - & 577 & 12.2 & 1.33 & 0.171 & 263 \\
\hline Co/Zr-SBA-15(17) & 5.0 & - & 592 & 12.3 & 1.36 & 0.150 & 250 \\
\hline Zr-SBA-15(38) & - & 38 & 667 & 11.7 & 1.58 & 0.160 & 262 \\
\hline Ni/Zr-SBA-15(38) & 4.8 & - & 530 & 11.7 & 1.17 & 0.099 & 247 \\
\hline Co/Zr-SBA-15(38) & 4.5 & - & 519 & 11.7 & 1.15 & 0.096 & 275 \\
\hline Zr-SBA-15(88) & - & 88 & 657 & 10.2 & 1.27 & 0.119 & 265 \\
\hline Ni/Zr-SBA-15(88) & 4.9 & - & 510 & 10.1 & 0.98 & 0.049 & 250 \\
\hline Co/Zr-SBA-15(88) & 5.3 & - & 517 & 10.1 & 0.96 & 0.055 & 250 \\
\hline
\end{tabular}

1 ICP-OES measurements; ${ }^{2}$ surface area determined by Brunauer-Emmett-Teller (BET) method; ${ }^{3}$ pore size calculated by Barrett-Joyner-Halenda (BJH) method; ${ }^{4}$ total volume at $\mathrm{P} / \mathrm{P}_{0} \approx 0.98 ;{ }^{5}$ determined from ammonia temperature-programmed desorption $\left(\mathrm{NH}_{3}\right.$-TPD) measurements; ${ }^{6}$ maximum of the $\mathrm{NH}_{3}$-TPD curve. Samples in oxide form.

For the Zr-SBA-15(x) supports a broad diffraction peak at around $22^{\circ}$ due to the amorphous silica walls is the only feature of the wide angle XRD pattern, since no indication of the presence of $\mathrm{ZrO}_{2}$ was detected. Similar results have been previously reported and they point to an easy and homogeneous dispersion of $\mathrm{Zr}$ species in the SBA-15 matrix [39]. Wide-angle XRD patterns of metal loaded catalysts after calcination are displayed in Figure 1b, showing the reflections of $\mathrm{NiO}$ (Joint Committee on Powder Diffraction Standards-JCPDS: 47-1049) and $\mathrm{Co}_{3} \mathrm{O}_{4}$ (JCPDS: 01-078-1970) phases, respectively. No significant differences in the intensities of these peaks are apparent for samples with different $\mathrm{Si} / \mathrm{Zr}$ ratios.
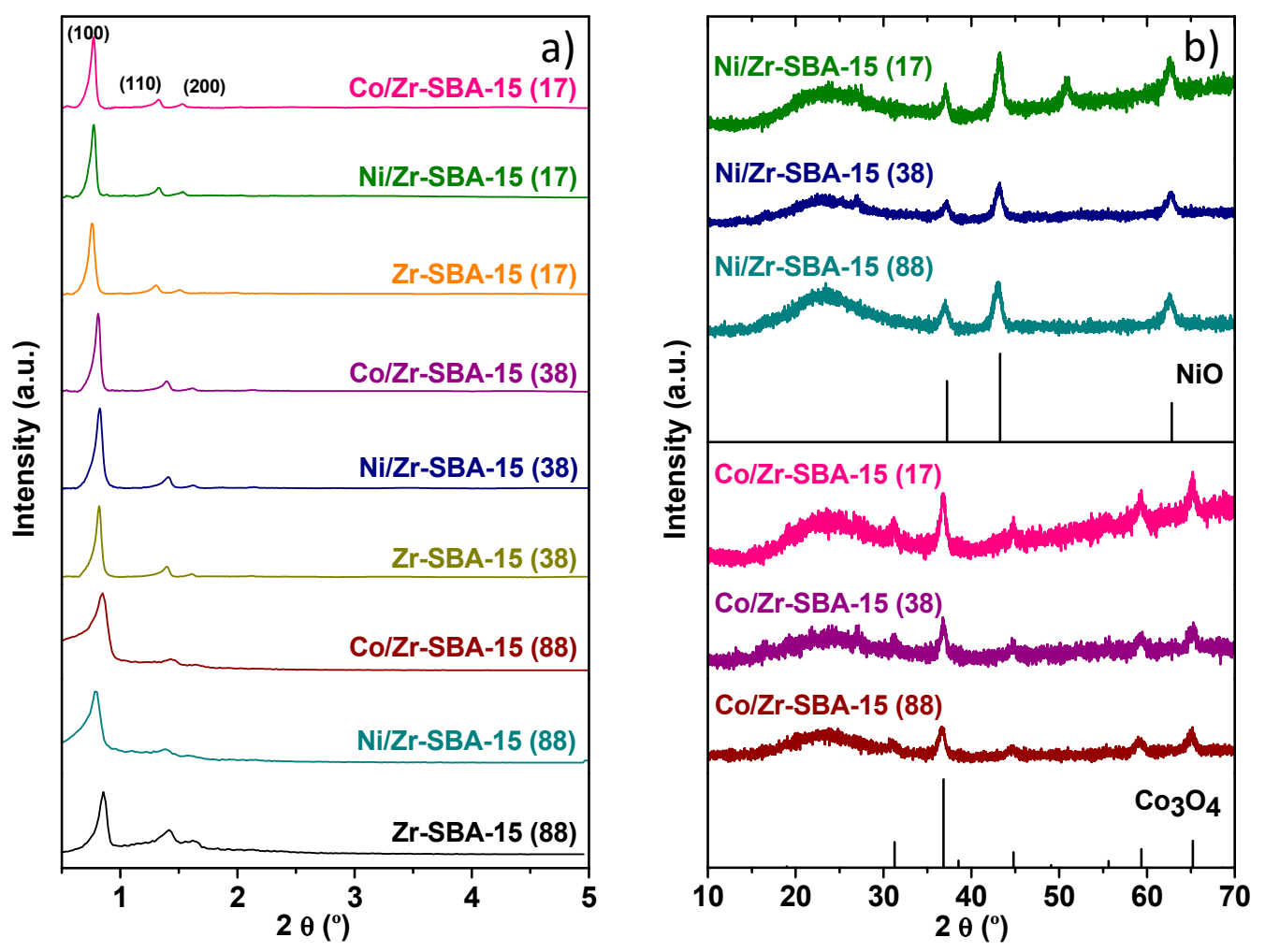

Figure 1. (a) Small-angle and (b) wide-angle XRD patterns of mesoporous M/Zr-SBA-15(x), including their corresponding bare $\mathrm{Zr}-\mathrm{SBA}-15(\mathrm{x}), \mathrm{NiO}$ and $\mathrm{Co}_{3} \mathrm{O}_{4}$ as references. 
$\mathrm{N}_{2}$ adsorption isotherms for all the samples are shown in Figure 2. In all cases, they correspond to type IV with an H1 hysteresis loop. This profile is characteristic of ordered mesoporous materials with narrow pore size distribution, as expected for Zr-SBA-15 based materials [39-42]. As it is indicated by the main textural parameter gathered in Table 1, the Zr-SBA-15 samples with lower Si/Zr ratios present somewhat higher surface areas, pore diameters and pore volumes, which agrees well with the shift to lower angle of the (100) reflection observed by XRD. The mean pore size enlargement with the $\mathrm{Zr}$ amount could be also explained by an increase in the volume of the micelles (swelling effect) due to the dissolution of the zirconium precursor inside them during the synthesis step. Similar phenomena were previously reported when aluminum isopropoxide and titanocene dichloride were used as metal precursors [43,44]. Incorporation of $\mathrm{Ni}$ and Co results in a clear decrease of adsorption capacity, which is very similar for both metals in all the supports. Accordingly, surface area is reduced between $15 \%$ and $22 \%$ upon metal addition, while pore volume drops by around $30 \%$ in comparison with the Zr-SBA-15 support. In contrast, pore diameter is basically not modified by the presence of metals. These results suggest that a significant number of metallic particles are located within the mesoporous channels.
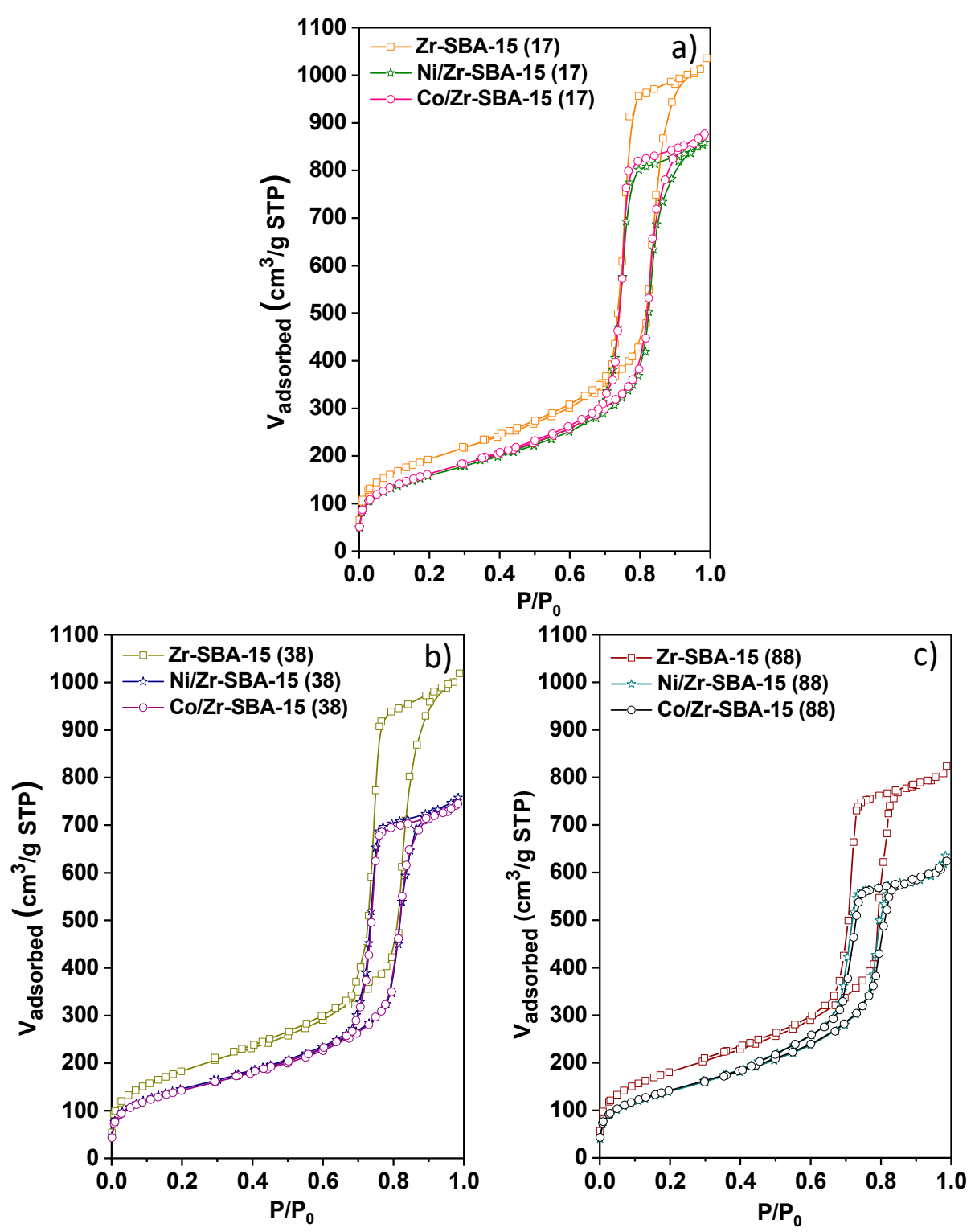

Figure 2. $\mathrm{N}_{2}$-physisorption isotherms of mesoporous (a) M/Zr-SBA-15(17), (b) M/Zr-SBA-15(38) and (c) M/Zr-SBA-15(88). 
In order to get further insights about the distribution of the nanoparticles, transmission electron microscopy (TEM) was performed. Images of the different M/Zr-SBA-15(x) catalysts are shown in Figure 3. They reveal the presence of abundant particles of $\mathrm{Co}$ or Ni phases distributed over the mesoporous support, which present a well-ordered channel network. Some cubic crystallites of $\mathrm{NiO}$ are especially visible for the Ni/Zr-SBA-15(38) sample but, in most of the cases, more rounded agglomerates are present. Overall, observed particles are rather large for the two metals, with many of them exceeding a diameter of $30 \mathrm{~nm}$, and accordingly, they are mainly located outside the channels, in the external surface. However, darker areas with more elongated shapes, which are particularly visible for Co/Zr-SBA-15(38), denote the occurrence of metal inclusions inside the mesopores, clustering in certain areas. This uneven distribution of the metallic phases is consistent with the textural characteristics inferred from the $\mathrm{N}_{2}$ adsorption isotherms, which indicate a limited modification of the mesoporous network upon $\mathrm{Ni}$ and Co deposition. Analyzing the particle size distributions revealed a special interaction between $\mathrm{Co}$ and $\mathrm{Zr}$ species since higher amounts of $\mathrm{Zr}$ (lower Si/Zr ratios) lead to smaller particles sizes, reaching a relative abundance above $20 \%$ of nanoparticles with diameter below $10 \mathrm{~nm}$ for Co/Zr-SBA-15(17). However, no such positive effect has been found between Ni distribution and $\mathrm{Zr}$ amount. It is important to clarify that particles smaller than $10 \mathrm{~nm}$ were difficult to measure due to the low contrast between support and nanoparticles as well as the limitations of the microscope. These restrictions can diminish its contribution over the total amount, although no large differences are expected.

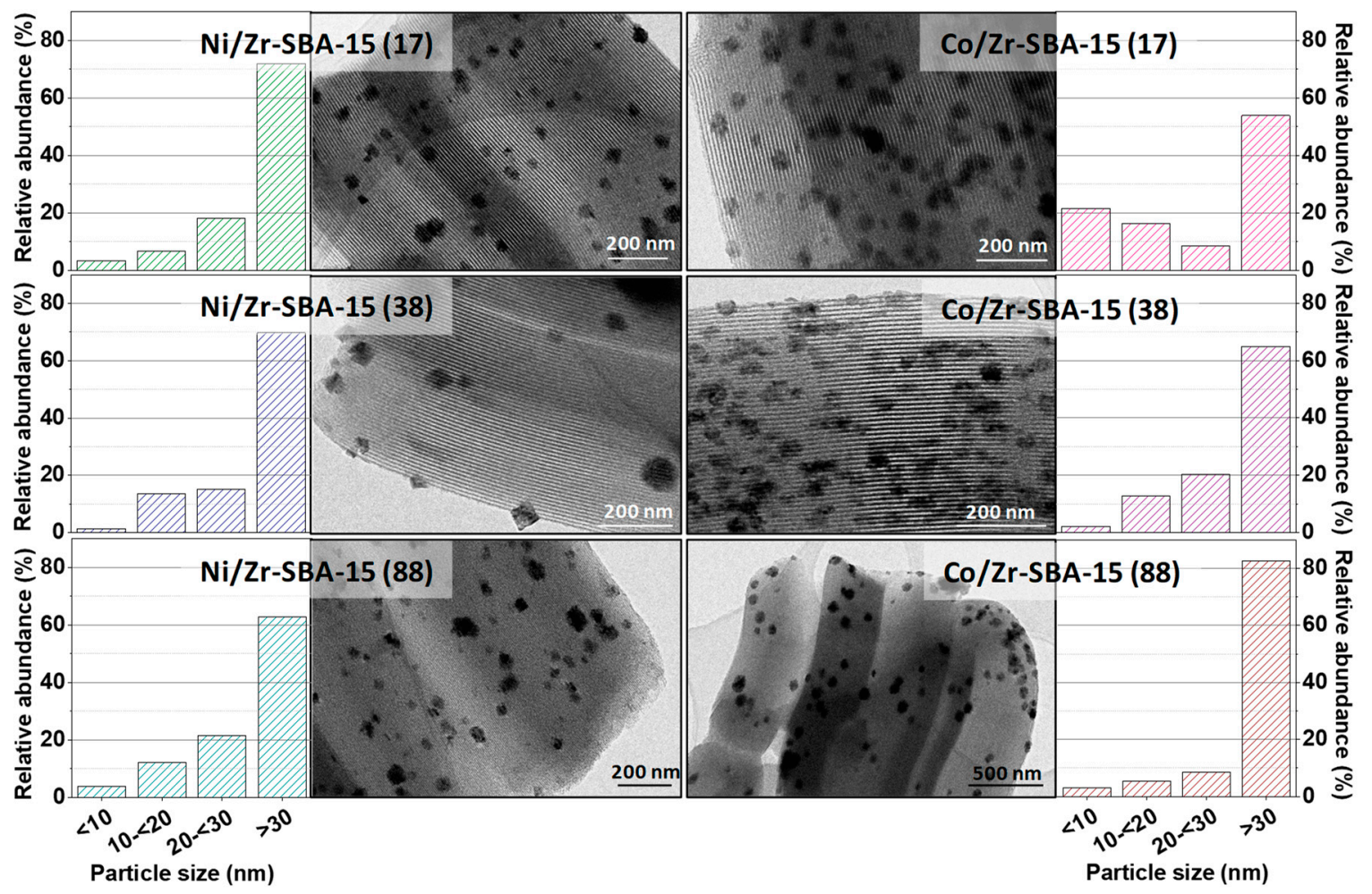

Figure 3. TEM micrographs and particle size distributions of the studied catalysts.

Acidity of the supports and catalysts was determined from $\mathrm{NH}_{3}$-TPD measurements (see Table 1). $\mathrm{Zr}$ incorporation in the mesostructured silica generates acidic sites, mainly of Lewis type [45]. In accordance with previous studies [41,46], the acidity of the Zr-SBA-15 samples increases with the concentration of $\mathrm{Zr}$ from $0.119 \mathrm{meq} \cdot \mathrm{g}^{-1}$ for the material with the Si/Zr ratio of 88 to $0.244 \mathrm{meq} \cdot \mathrm{g}^{-1}$ for that with $\mathrm{Si} / \mathrm{Zr}$ ratio of 17 . Similarly, the temperature of the maximum of desorption shifts to slightly higher values with reducing the $\mathrm{Zr}$ content. The addition of both Co and Ni remarkably reduce the number of acidic sites with a not obvious difference between the effect of each metal. Specifically, for the 
samples with lower $\mathrm{Zr}$ content, the acidity drops to less than $47 \%$ after the active phase incorporation. This observation suggests that acidic centers favor the nucleation of metal phases.

In conclusion, metallic phases are located mainly on the external surface area although smaller particle sizes are observed inside of the pores. The increase of acidity leads to a reduction of the particle size of Co species, denoting an interaction between $\mathrm{Co}$ and $\mathrm{Zr}$ sites.

\subsection{Catalytic Results}

Physicochemical and structural properties analyses confirmed that the synthesized materials possess suitable characteristics to study the influence of acidity and metal-support interactions in the hydrotreating of methyl esters with the objective of producing hydrocarbons in the diesel range. The catalytic performances of these materials over $6 \mathrm{~h}$ of reaction in a continuous flow reactor at $300^{\circ} \mathrm{C}$ and 30 bar of hydrogen pressure are presented and discussed below.

Conversion of the substrate over Ni/Zr-SBA-15(x) and Co/Zr-SBA-15(x) is depicted in Figure 4a,b, respectively. For all the tested catalysts, values greater than $70 \%$ were achieved, denoting that they are highly active in the studied reaction. The $\mathrm{Si} / \mathrm{Zr}$ molar ratio plays an important role in the activity of the materials, the lower Si/Zr the higher acidity and the higher ester transformation, independently of the metallic phase. This behavior is due to the presence of the acidic sites which help to lower the electron density on the metal surfaces. This fact favors that the molecules are less strongly adsorbed (increase of the desorption rate), favoring the hydrodeoxygenation process [47]. These experimental results are consistent with those found in literature, which associated the increase on the hydrogenation rate of the $\mathrm{C}=\mathrm{C}$ and $\mathrm{C}=\mathrm{O}$ bonds to the presence of acid centers with medium-low strength in the catalyst $[29,47,48]$. Comparing both metallic phases, cobalt based catalysts are more active and stable along the time on stream, reaching conversions above $90 \%$ in all cases. Ni/Zr-SBA-15(88) presents the lowest activity among the mesostructured bifunctional catalysts. This can be attributed to its lower acidity $\left(0.049\right.$ meq $\left.\mathrm{NH}_{3} / \mathrm{g}_{\text {sup }}\right)$ and specific surface area $\left(510 \mathrm{~m}^{2} / \mathrm{g}_{\text {sup }}\right)$ and larger nickel nanoparticles, in addition to the intrinsically lower activity of $\mathrm{Ni}$ compared to $\mathrm{Co}$, as has been previously reported by our group [29]. In all cases, the conversion tends to fall along the time on stream, probably due to the presence of oxygenated intermediates (stearic acid, octadecanol) that remain adsorbed on the surface of the active species favoring their deactivation $[49,50]$.
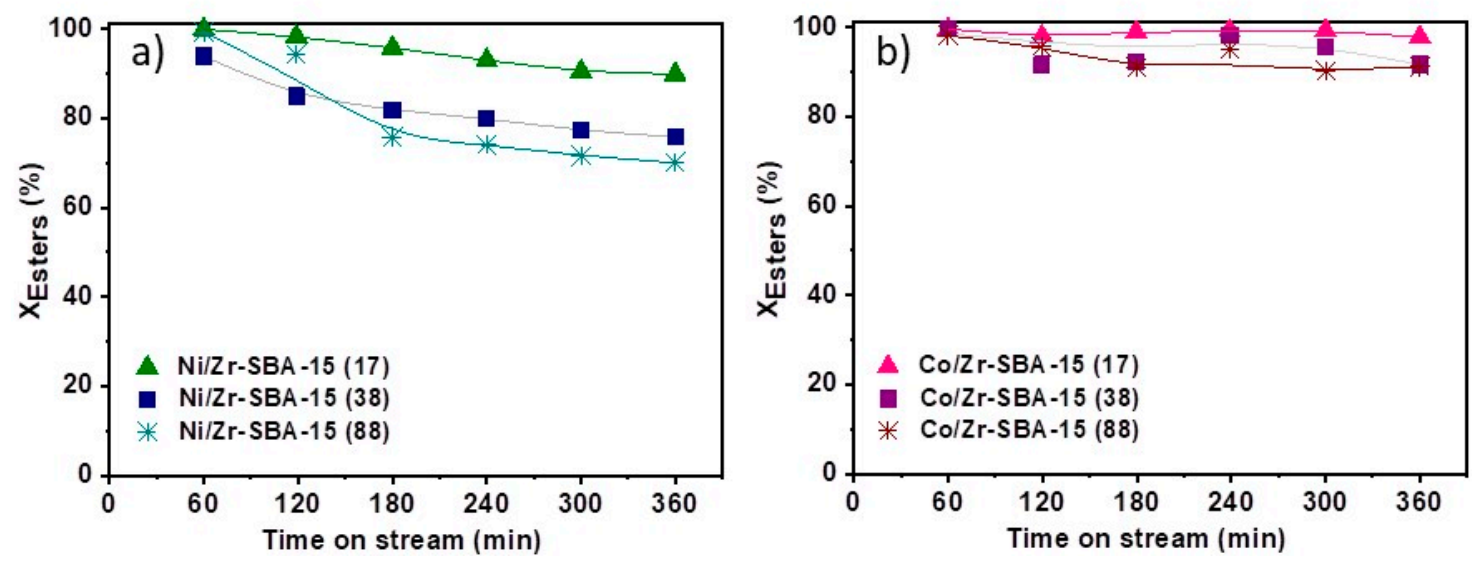

Figure 4. Conversion of methyl esters as a function of time on stream: (a) Ni/Zr-SBA-15(x) and (b) Co/Zr-SBA-15(x).

Figure 5 shows the overall hydrocarbon yield in the range $C_{11}-C_{20}$, which includes both linear and non-linear paraffins, the contribution of the latter being lower than $10 \%$ in all the catalytic tests. This parameter can greatly differ from the conversion because of lighter hydrocarbons' formation via hydrocracking or the presence of oxygenated reaction intermediates (especially at longer reaction times) which are not considered in this fraction. This is the case for Ni/Zr-SBA-15(x) samples, in which 
the incorporation of the metallic phase to $\mathrm{Zr}-\mathrm{SBA}-15$ does not result in a stable and highly selective catalyst under the studied reaction conditions. Similar behavior presents the Co/Zr-SBA-15(88) material. Although it contains some acidity $\left(0.055 \mathrm{meq} \mathrm{NH}_{3} / \mathrm{g}_{\text {sup }}\right)$ that favors the conversion of methyl esters, both the amount and the strength of its acid sites are not high enough to complete their transformation into n-paraffins. The highest yields ( $>95 \%$ ) and conversions (ca. 100\%) along the time on stream are reached using Co/Zr-SBA-15(17), suggesting that the presence of a higher amount of zirconium, higher surface area, lower particle sizes and the existence of adequate metal-support interactions are needed to achieve an active, stable and selective catalytic system.
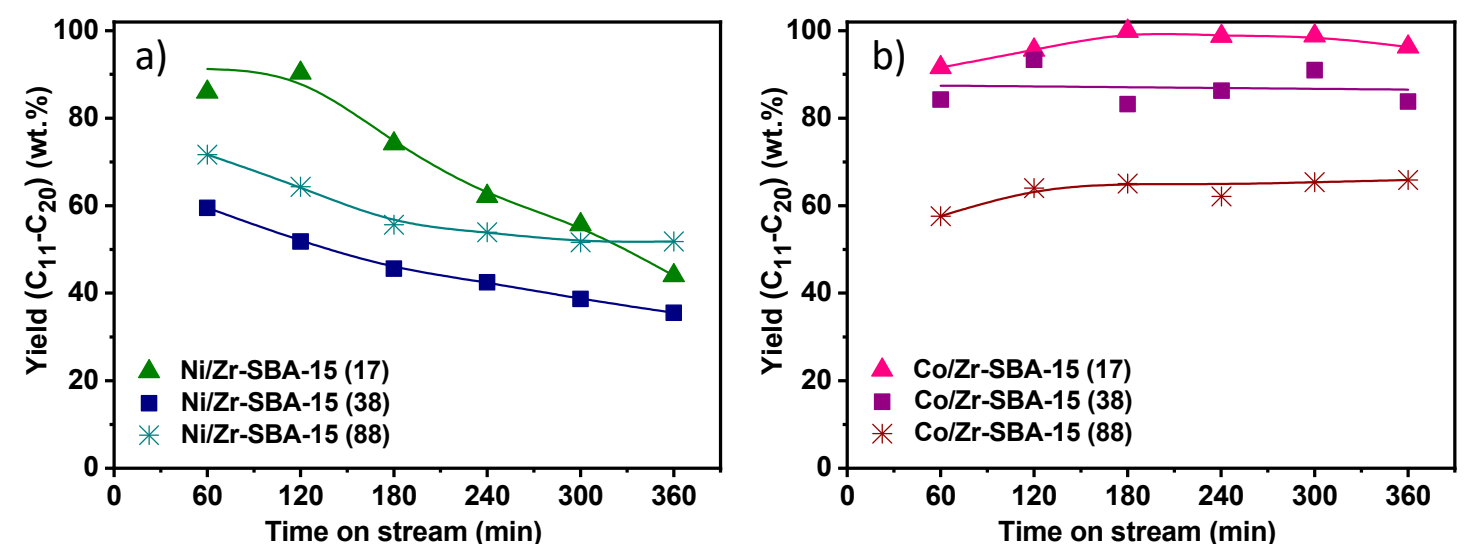

Figure 5. Yield to hydrocarbons in the range $C_{11}-C_{20}$ (a) Ni/Zr-SBA-15(x) and (b) Co/Zr-SBA-15(x).

As has been mentioned in the introduction, hydrotreating of methyl esters can follow two paths: (i) HDO, which results in linear hydrocarbons with even numbers (mostly $n-\mathrm{C}_{18}$ as the feedstock composition contains $\approx 80 \%$ of methyl esters with $\mathrm{C}_{18}$ ) and $\mathrm{H}_{2} \mathrm{O}$; (ii) $\mathrm{HDC}$, which involves the production of linear hydrocarbons with odd numbers (mainly n- $\mathrm{C}_{17}$ ), $\mathrm{CH}_{4}$ and $\mathrm{CO} / \mathrm{CO}_{2}$. Conversion and yield provide an accurate overview about the catalytic behavior of the samples but do not give any evidence about the reaction route. However, relevant information can be extracted from the n-paraffin selectivity in the range $C_{11}-C_{20}$ (Figure 6). It can be observed that the product distribution by carbon atoms is mainly centered between $C_{14}$ and $C_{20}$, which agrees well with the chain-length of the starting ester mixture. This fact indicates that the main transformation routes are hydrodeoxygenation and decarboxylation/decarbonylation, with little contribution of hydrocracking reactions. Ni based catalysts produce mainly $n-C_{17}$ paraffins where the selectivity decreases with increasing amount of $\mathrm{Zr}$. In contrast, when Co-containing catalysts were used, $\mathrm{n}-\mathrm{C}_{17}$ formation declines and an enhanced selectivity towards $\mathrm{n}-\mathrm{C}_{18}$ was observed, particularly for the sample with higher $\mathrm{Zr}$ content.
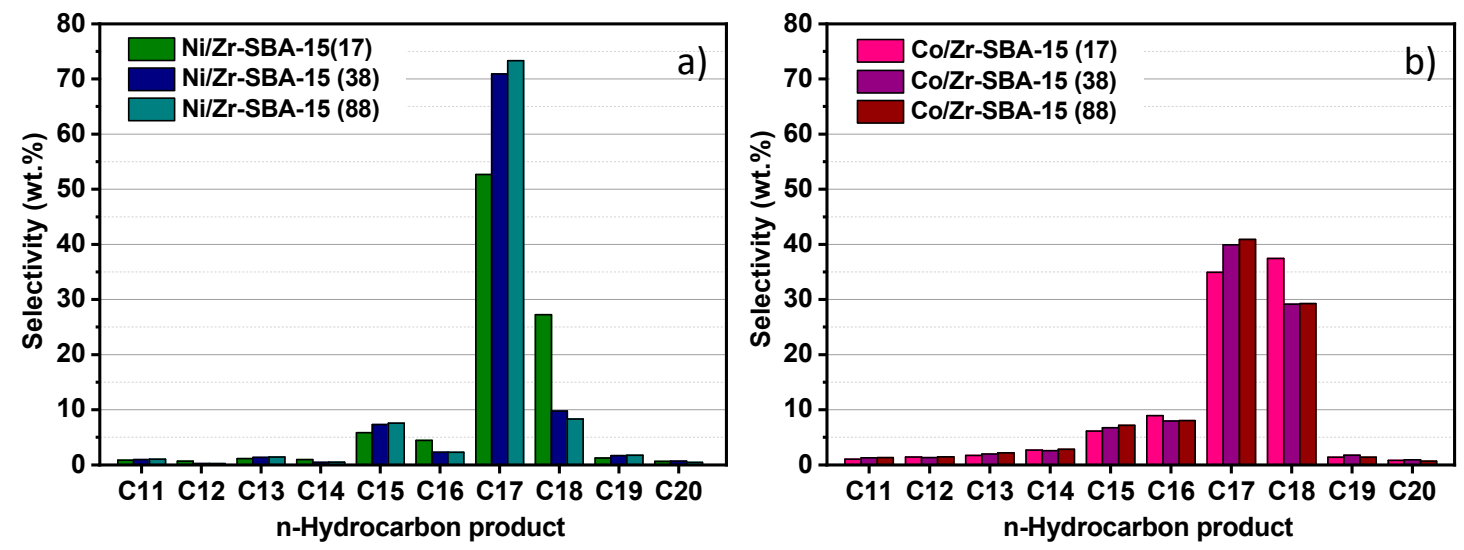

Figure 6. Selectivity to n-paraffins for the catalyst (a) Ni/Zr-SBA-15(x) and (b) Co/Zr-SBA-15(x) after 6 $\mathrm{h}$ on stream. 
Figure 7 shows the variation of $n-C_{18} /\left(n-C_{18}+n-C_{17}\right)$ ratio along the time on stream, which is a parameter directly linked to the relative extension of the HDO route in comparison with HDC. Values above $0.5 \mathrm{imply}$ that the process takes place to a greater degree via HDO than via HDC. When both metallic systems with the same support are compared, Co leads to higher $n-C_{18} /\left(n-C_{18}+n-C_{17}\right)$ values, regardless of the $\mathrm{Si} / \mathrm{Zr}$ molar ratio. In contrast, $\mathrm{Ni}$ impregnated materials present lower values, denoting that this metal favors the decarboxylation/decarbonylation pathway in agreement with previous literature [51,52]. This route is associated with the formation of $\mathrm{COx}$, which can be further transformed into $\mathrm{CH}_{4}$ by means of methanation reactions $\left(\mathrm{CO}+3 \mathrm{H}_{2} \leftrightarrow \mathrm{CH}_{4}+\mathrm{H}_{2} \mathrm{O}\right.$ and $\mathrm{CO}_{2}+4 \mathrm{H}_{2}$ $\left.\leftrightarrow \mathrm{CH}_{4}+2 \mathrm{H}_{2} \mathrm{O}\right)[23,53]$. This secondary transformation involves additional hydrogen consumption, which makes this pathway less attractive. On the other hand, the presence of acidity plays an important role not only in the conversion of the methyl esters but also in the way in which is taking place this transformation. The incorporation of acidic species, such as zirconium, into the siliceous support promotes the formation of $\mathrm{n}-\mathrm{C}_{18}$. Thus, as shown in Figure 7, the lower $\mathrm{Si} / \mathrm{Zr}$ molar ratio the higher $\mathrm{n}-\mathrm{C}_{18} /\left(\mathrm{n}-\mathrm{C}_{18}+\mathrm{n}-\mathrm{C}_{17}\right)$ achieved. These results reveal the importance of an adequate combination between acidity (amount of acid sites and strength) and metal type in order to promote mostly HDO reactions. Accordingly, it can be concluded that Co/Zr-SBA-15(17) exhibits suitable physicochemical properties to increase the hydrogenation rate of the $\mathrm{C}=\mathrm{O}$ bond and achieve a n- $\mathrm{C}_{18} /\left(\mathrm{n}-\mathrm{C}_{18}+\mathrm{n}-\mathrm{C}_{17}\right)$ ratio above 0.5 while keeping the esters conversion close to $100 \%$ along the time on stream.
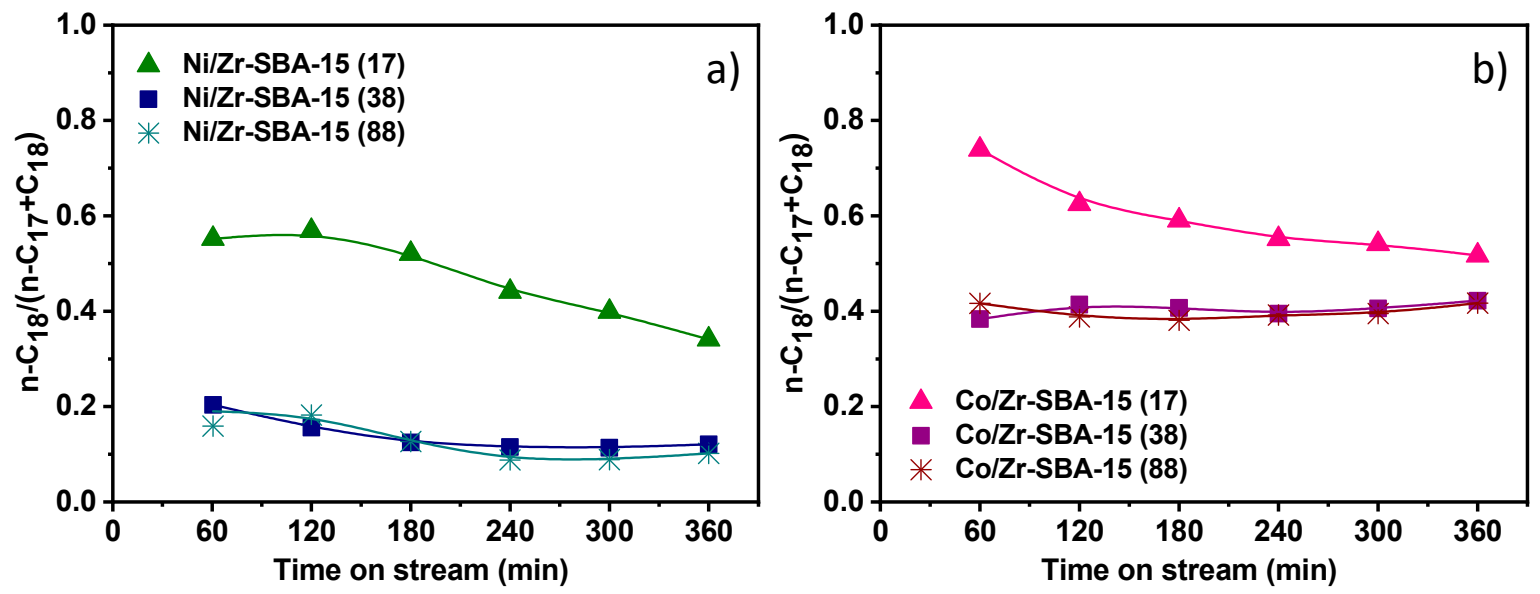

Figure 7. Influence of the metallic element and $\mathrm{Si} / \mathrm{Zr}$ ratio on $\mathrm{n}-\mathrm{C}_{18} /\left(\mathrm{n}-\mathrm{C}_{17}+\mathrm{n}-\mathrm{C}_{18}\right)$ progression along the reaction time: (a) Ni/Zr-SBA-15(x) and (b) Co/Zr-SBA-15(x).

\section{Materials and Methods}

\subsection{Materials}

Hydrochloric acid ( $\mathrm{HCl}, 35 \%$, Scharlau, Barcelona, Spain), tetraethyl orthosilicate (TEOS, 98\%, Sigma-Aldrich, St. Louis, MO, USA), Pluronic P123 ( $\mathrm{M}_{\mathrm{n}} \sim 5800$, Sigma-Aldrich, St. Louis, MO, USA) and zirconocene dichloride (98\%, Sigma-Aldrich, St. Louis, MO, USA) were used for the synthesis of Zr-SBA-15. Cobalt(II) nitrate hexahydrate (98\%, Sigma-Aldrich, St. Louis, MO, USA) and nickel(II) nitrate hexahydrate (98\%, Sigma-Aldrich, St. Louis, MO, USA) were employed as metal precursors. For catalytic tests, n-heptane (99\%, HPLC grade, Scharlau, Barcelona, Spain) without further purification was used as a solvent, whilst molecular hydrogen (99.999\%, Praxair, Madrid, Spain) and methyl oleate (70\%, Sigma-Aldrich, St. Louis, MO, USA, detailed composition has been published in a previous work [54]) were reactants. For the quantification of methyl esters, methyl heptadecanoate ( $\geq 99 \%$, Sigma-Aldrich, St. Louis, MO, USA) was used as internal standard and a mixture of fatty acid methyl esters (F.A.M.E. mix $\mathrm{C}_{8}-\mathrm{C}_{22}$, Supelco, St. Louis, MO, USA) and an alkane standard solution $\left(\mathrm{C}_{8}-\mathrm{C}_{20}\right.$, analytical standard, Supelco, St. Louis, MO, USA ) were used as reference materials. 


\subsection{Catalyst Preparations}

Direct synthesis of Zr-SBA-15 samples, with varying Si/Zr ratios, was performed following a method previously described by Iglesias et al. [43]. In a typical synthesis, $4 \mathrm{~g}$ of Pluronic 123 was dissolved in $125 \mathrm{~mL}$ of a $\mathrm{HCl} 0.67 \mathrm{M}$ solution at room temperature under gentle agitation until complete dissolution of the surfactant. Thereafter, the proper amount of zirconocene dichloride (precursor of zirconium) was added to obtain the desired $\mathrm{Si} / \mathrm{Zr}$ molar ratio. The resulting suspension was stirred for $3 \mathrm{~h}$ at $40{ }^{\circ} \mathrm{C}$. Then, $8.63 \mathrm{~g}$ of TEOS were added and kept under agitation for $20 \mathrm{~h}$ at the same temperature. Subsequently, the mixture was hydrothermally aged at $130^{\circ} \mathrm{C}$ for $24 \mathrm{~h}$. The solid product was recovered by filtration and dried at room temperature overnight. Finally, the surfactant was removed by calcination at $5500^{\circ} \mathrm{C}$ for $5 \mathrm{~h}$ with a heating ramp of $1.8^{\circ} \mathrm{C} / \mathrm{min}$.

Aqueous solutions of $\mathrm{Ni}\left(\mathrm{NO}_{3}\right)_{2} \cdot 6 \mathrm{H}_{2} \mathrm{O}$ and $\mathrm{Co}\left(\mathrm{NO}_{3}\right)_{2} \cdot 6 \mathrm{H}_{2} \mathrm{O}$, with the proper concentration to obtain $5 \mathrm{wt} . \%$ loading of $\mathrm{Ni}$ or $\mathrm{Co}$ in the final material, were prepared and added to the supports by incipient wetness impregnation. The resultant solids were dried overnight and calcined at $550{ }^{\circ} \mathrm{C}$ for $5 \mathrm{~h}$. The catalysts are named M/Zr-SBA-15(x), where M corresponds to Ni or Co in their corresponding oxide form and $x$ to the Si/Zr molar ratio.

\subsection{Catalyst Characterization Techniques}

Synthesized catalysts were characterized by different analytic techniques in order to determine their physicochemical and structural properties and to correlate them with the catalytic results. Metal content was measured by inductively coupled plasma optical emission spectrometry (ICP-OES) on an Optima 7300 AD system (Perkin Elmer, Waltham, MA, USA). Powder X-ray diffraction (XRD) was performed on a X'Pert PRO diffractometer (Philips, Amsterdam, Netherlands) with $\mathrm{Cu}-\mathrm{K} \alpha$ radiation $(\lambda=1.542 \AA)$. To evaluate the textural properties, $\mathrm{N}_{2}$ adsorption-desorption isotherms were measured on a QUADRASORB (Quantachrome, Boynton Beach, FL, USA) unit at $-196{ }^{\circ} \mathrm{C}$. Total pore volume was determined from the $\mathrm{N}_{2}$ volume adsorbed at $\mathrm{P} / \mathrm{P}_{0}=0.98$. Barrett-Joyner-Halenda (BJH) method was applied to the adsorption branch to calculate the pore size distribution and Brunauer-Emmett-Teller (BET) equation was used to calculate the specific surface area. Temperature programmed desorption tests of ammonia ( $\mathrm{NH}_{3-}$ TPD), using a $15 \% \mathrm{NH}_{3} / \mathrm{He}$ flow, were performed on an AUTOCHEM 2910 (Micromeritics, Norcross, GA, USA) setup equipped with a thermal conductivity detector in order to evaluate the acidic properties of the catalysts using the previously reported protocol [29]. Finally, transmission electron microscopy (TEM) images were obtained with a TECNAI 20T instrument (Philips, Amsterdam, Netherlands), operating at $200 \mathrm{kV}$.

\subsection{Catalytic Tests}

A mixture of esters diluted with n-heptane $(10 \mathrm{v} / \mathrm{v} \%)$ was used as feedstock for the hydrotreating reactions. Experiments were carried out under continuous flow $(0.1 \mathrm{~mL} / \mathrm{min})$ in a fixed-bed tubular reactor with the catalytic bed placed inside upon a porous plate (MICROACTIVITY-REFERENCE, PID Eng and Tech, Madrid, Spain). The reactor was loaded with the pelletized catalyst (200 $\mathrm{mg}$ ) diluted by silicon carbide $(250-400 \mu \mathrm{m})$ in order to minimize hot spot effects and to improve the reaction-heat transfer. Catalysts were in situ reduced with a flow of pure hydrogen. Catalytic tests were conducted at $300^{\circ} \mathrm{C}$, with 30 bar of hydrogen and $20.4 \mathrm{~h}^{-1}$ (weight hourly space velocity-WHSV) for $6 \mathrm{~h}$. Liquid samples were cooled in a liquid/gas separator and collected every hour. Quantification of esters and hydrocarbons was carried out in a gas chromatograph (Agilent 7890, Agilent, Santa Clara, CA, USA) equipped with two columns (HP-5 and HP-Innowax) and two flame ionization detectors (FIDs). 


\section{Conclusions}

$\mathrm{Ni}$ and Co metals have been incorporated into a series of mesoporous Zr-SBA-15 samples with different $\mathrm{Si} / \mathrm{Zr}$ molar ratios and studied as catalysts in the production of green diesel by hydrotreating of methyl esters. Increasing zirconium content in the support led to a slight decrease of the mesoscopic order, larger unit cells and a higher number of acid sites. A limited blocking of the mesoporous network was observed upon $\mathrm{Ni}$ and Co incorporation. Besides, smaller particles of Co were formed when increasing the $\mathrm{Zr}$ amount, denoting the existence of a special interaction between $\mathrm{Co}$ and $\mathrm{Zr}$.

Catalytic tests evidenced that lower $\mathrm{Si} / \mathrm{Zr}$ ratios resulted in enhanced methyl esters conversions $(>90 \%)$, although an adequate metal-support combination was required to attain high hydrocarbon yields in the $C_{11}-C_{20}$ range via hydrodeoxygenation pathway. Analyzing the active phase, Ni based materials showed to be intrinsically less active than the Co-containing catalysts, presenting methyl esters conversions above $70 \%$ and $90 \%$, respectively. In all the experiments, $C_{17}$ and $C_{18}$ hydrocarbons were identified as the major products, showing a small extension of hydrocracking reactions due to the mild acidity of the catalysts.

The favored catalytic route was also studied in this work. In this regard, Co/Zr-SBA-15(x) catalysts led to the formation of $\mathrm{n}-\mathrm{C}_{18}$ at higher extension than the corresponding Ni-based counterpart. In particular, the Co/Zr-SBA-15(17) sample exhibited a remarkable and rather stable catalytic activity along time on stream and high yield of long-chain hydrocarbons $(>90 \%)$ while promoting the HDO pathway versus the HDC route $\left(n-C_{18} /\left(n-C_{18}+n-C_{17}\right)>0.5\right)$. This enhanced activity when increasing $\mathrm{Zr}$ content in the walls of SBA-15 suggests the existence of a synergistic effect between Co and $\mathrm{Zr}$, resulting in an interesting catalytic system for hydrotreating reactions.

Author Contributions: C.O.-H. has performed the experimental part under the supervision of J.M.C. and D.P.S. The manuscript has been written through the contribution of all authors. All authors have read and agreed to the published version of the manuscript.

Funding: This research was funded by the regional government of Madrid and European Structural Funds through RESTOENE project (P2009/ENE-1743) and by the Spanish Ministry of Economy and Competitiveness through LIGCATUP project (ENE2011-29643-C02-01).

Acknowledgments: The authors acknowledge Fernando Picó, María Eugenia di Falco and Laura García for performing XRD, TEM, $\mathrm{N}_{2}$-physisorption and ICP-OES measurements.

Conflicts of Interest: The authors declare no conflict of interest.

\section{References}

1. Huber, G.W.; Corma, A. Synergies between bio- and oil refineries for the production of fuels from biomass. Angew. Chem. Int. Ed. 2007, 46, 7184-7201. [CrossRef]

2. Ramadhas, A.S.; Jayaraj, S.; Muraleedharan, C. Biodiesel production from high FFAA rubber seed oil. Fuel 2005, 84, 335-340. [CrossRef]

3. Singh Chouhan, A.P.; Sarma, A.K. Modern heterogeneous catalysts for biodiesel production: A comprehensive review. Renew. Sustain. Energy Rev. 2011, 15, 4378-4399. [CrossRef]

4. Kiss, A.A.; Dimian, A.C.; Rothenberg, G. Solid acid catalysts for biodiesel production-Towards sustainable energy. Adv. Synth. Catal. 2006, 348, 75-81. [CrossRef]

5. Karimi, B.; Mirzaei, H.M.; Mobaraki, A. Periodic mesoporous organosilica functionalized sulfonic acids as highly efficient and recyclable catalysts in biodiesel production. Catal. Sci. Technol. 2012, 2, 828-834. [CrossRef]

6. Jiang, Y.J.; Liu, X.L.; Chen, Y.F.; Zhou, L.Y.; He, Y.; Ma, L.; Gao, J. Pickering emulsion stabilized by lipase-containing periodic mesoporous organosilica particles: A robust biocatalyst system for biodiesel production. Bioresour. Technol. 2014, 153, 278-283. [CrossRef]

7. Melero, J.A.; Bautista, L.F.; Morales, G.; Iglesias, J.; Briones, D. Biodiesel production with heterogeneous sulfonic acid-functionalized mesostructured catalysts. Energy Fuels 2009, 23, 539-547. [CrossRef] 
8. Reyes, J.F.; Sepúlveda, M.A. PM-10 emissions and power of a diesel engine fueled with crude and refined biodiesel from salmon oil. Fuel 2006, 85, 1714-1719. [CrossRef]

9. Lapuerta, M.; Armas, O.; Rodriguez-Fernandez, J. Effect of biodiesel fuels on diesel engine emissions. Prog. Energy Combust. Sci. 2008, 34, 198-223. [CrossRef]

10. Sannita, E.; Aliakbarian, B.; Casazza, A.A.; Perego, P.; Busca, G. Medium-temperature conversion of biomass and wastes into liquid products, a review. Renew. Sustain. Energy Rev. 2012, 16, 6455-6475. [CrossRef]

11. Twaiq, F.A.; Zabini, N.A.; Bhatia, S. Catalytic conversion of palm oil to hydrocarbons: Performance of various zeolite catalysts. Ind. Eng. Chem. Res. 1999, 38, 3230-3237. [CrossRef]

12. Idem, R.O.; Katikaneni, S.P.R.; Bakhshi, N.N. Catalytic conversion of canola oil to fuels and chemicals: Roles of catalyst acidity, basicity and shape selectivity on product distribution. Fuel Process. Technol. 1997, 51, 101-125. [CrossRef]

13. Twaiq, F.A.; Mohamed, A.R.; Bhatia, S. Liquid hydrocarbon fuels from palm oil by catalytic cracking over aluminosilicate mesoporous catalysts with various Si/Al ratios. Microporous Mesoporous Mater. 2003, 64, 95-107. [CrossRef]

14. Ooi, Y.S.; Zakaria, R.; Mohamed, A.R.; Bhatia, S. Synthesis of composite material MCM-41/beta and its catalytic performance in waste used palm oil cracking. Appl. Catal. A Gen. 2004, 274, 15-23. [CrossRef]

15. Ngo, T.; Kim, J.; Kim, S.K.; Kim, S. Pyrolysis of soybean oil with H-ZSM5 (Proton-exchange of Zeolite Socony Mobil \#5) and MCM41 (Mobil Composition of Matter No. 41) catalysts in a fixed-bed reactor. Energy 2010, $35,2723-2728$.

16. Quirino, R.L.; Tavares, A.P.; Peres, A.C.; Rubim, J.C.; Suarez, P.A. Studying the influence of alumina catalysts doped with tin and zinc oxides in the soybean oil pyrolysis reaction. J. Am. Oil Chem. Soc. 2009, 86, 167-172. [CrossRef]

17. Serrano, D.P.; Escola, J.M.; Briones, L.; Arroyo, M. Selective hydrodecarboxylation of fatty acids into long-chain hydrocarbons catalyzed by Pd/Al-SBA-15. Microporous Mesoporous Mater. 2019, 280, 88-96. [CrossRef]

18. Kordulis, C.; Bourikas, K.; Gousi, M.; Kordouli, E.; Lycourghiotis, A. Developtment of nickel based catalysts for the transformation of natural triglycerides and related compounds into green diesel: A critical review. Appl. Catal. B Environ. 2016, 181, 156-196. [CrossRef]

19. Šimáček, P.; Kubička, D.; Šebor, G.; Pospíšil, M. Hydroprocessed rapeseed oil as a source of hydrocarbon-based biodiesel. Fuel 2009, 88, 456-460. [CrossRef]

20. Madsen, A.T.; Ahmed, E.H.; Christensen, C.H.; Fehrmann, R.; Riisager, A. Hydrodeoxygenation of waste fat for diesel production: Study on model feed with Pt/alumina catalyst. Fuel 2011, 90, 3433-3438. [CrossRef]

21. Snåre, M.; Kubičová, I.; Mäki-Arvela, P.; Eränen, K.; Murzin, D.Y. Heterogeneous catalytic deoxygenation of stearic acid for production of biodiesel. Ind. Eng. Chem. Res. 2006, 45, 5708-5715. [CrossRef]

22. Janampelli, S.; Darbha, S. Metal oxide-promoted hydrodeoxygenation activity of platinum in $\mathrm{Pt}-\mathrm{MO}_{\mathrm{x}} / \mathrm{Al}_{2} \mathrm{O}_{3}$ catalysts for green diesel production. Energ. Fuels 2018, 12, 12630-12643. [CrossRef]

23. Duan, J.; Han, J.; Sun, H.; Chen, P.; Lou, H.; Zheng, X. Diesel-like hydrocarbons obtained by direct hydrodeoxygenation of sunflower oil over Pd/AlSBA-15 catalysts. Catal. Commun. 2012, 17, 76-80. [CrossRef]

24. Kubička, D.; Bejblová, M.; Vlk, J. Conversion of vegetable oils into hydrocarbons over CoMo/MCM-41 catalysts. Top. Catal. 2010, 53, 168-178. [CrossRef]

25. Kikhtyanin, O.V.; Rubanov, A.E.; Ayupov, A.B.; Echevsky, G.V. Hydroconversion of sunflower oil on Pd/SAPO-31 catalyst. Fuel 2010, 89, 3085-3092. [CrossRef]

26. Wang, C.; Liu, Q.; Song, J.; Li, W.; Li, P.; Xu, R.; Ma, H.; Tian, Z. High quality diesel-range alkanes production via a single-step hydrotreatment of vegetable oil over Ni/zeolite catalyst. Catal. Today 2014, 234, 153-160. [CrossRef]

27. Sotelo-Boyás, R.; Liu, Y.; Minowa, T. Renewable diesel production from the hydrotreating of rapeseed oil with Pt/Zeolite and $\mathrm{NiMo} / \mathrm{Al}_{2} \mathrm{O}_{3}$ catalysts. Ind. Eng. Chem. Res. 2011, 50, 2791-2799. [CrossRef]

28. Murata, K.; Liu, Y.; Inaba, M.; Takahara, I. Production of synthetic diesel by hydrotreatment of jatropha oils using Pt-Re/H-ZSM-5 catalyst. Energy Fuels 2010, 24, 2404-2409. [CrossRef]

29. Ochoa-Hernández, C.; Yang, Y.; Pizarro, P.; de la Peña O’Shea, V.A.; Coronado, J.M.; Serrano, D.P. Hydrocarbons production through hydrotreating of methyl esters over Ni and Co supported on SBA-15 and Al-SBA-15. Catal. Today 2013, 210, 81-88. [CrossRef] 
30. Jiang, B.; Zhu, T.; Song, H.; Li, F. Hydrodeoxygenation and hydrodesulfurization over Fe promoted $\mathrm{Ni}_{2} \mathrm{P} / \mathrm{SBA}-15$ catalyst. J. Alloys Compd. 2019, 806, 254-262. [CrossRef]

31. Vu, T.A.; Le, G.H.; Pham, G.T.T.; Tran, H.T.K.; Dang, P.T.; Nguyen, M.B.; Vu, L.D.; Lee, G.D. Highly catalytic performance of novel Ni-Cu containing SBA-15 materials in the hydrodeoxygenation of guaiacol. Biointerface Res. Appl. Chem. 2018, 8, 3339-3343.

32. Wang, L.; Li, C.; Jin, S.; Li, W.; Liang, C. Hydrodeoxygenation of dibenzofuran over SBA-15 supported Pt, Pd, and Ru catalysts. Catal. Lett. 2014, 144, 809-816. [CrossRef]

33. Yang, Y.; Ochoa-Hernández, C.; De La Peña O'Shea, V.A.; Pizarro, P.; Coronado, J.M.; Serrano, D.P. Transition metal phosphide nanoparticles supported on SBA-15 as highly selective hydrodeoxygenation catalysts for the production of advanced biofuels. J. Nanosci. Nanotechnol. 2015, 15, 6642-6650. [CrossRef] [PubMed]

34. Li, Z.; Wu, J.; Yu, J.; Han, D.; Wu, L.; Li, J. Effect of incorporation manner of Zr on the Co/SBA-15 catalyst for the Fischer-Tropsch synthesis. J. Mol. Catal. A Chem. 2016, 424, 384-392. [CrossRef]

35. Liu, Y.; Murata, K.; Okabe, K.; Hanaoka, T.; Sakanishi, K. Synthesis of Zr-grafted SBA-15 as an effective support for cobalt catalyst in fischer-tropsch synthesis. Chem. Lett. 2008, 37, 984-985. [CrossRef]

36. Ganiyu, S.A.; Alhooshani, K. Catalytic performance of NiMoS supported on (Zr)SBA-15 for hydrodesulfurization of diesel: Insight into a one-step calcination and reduction strategy during sulfidation. Energy Fuels 2019, 33, 3047-3056. [CrossRef]

37. Gutiérrez, O.Y.; Pérez, F.; Fuentes, G.A.; Bokhimi, X.; Klimova, T. Deep HDS over NiMo/Zr-SBA-15 catalysts with varying MoO3 loading. Catal. Today 2008, 130, 292-301. [CrossRef]

38. Garg, S.; Soni, K.; Kumaran, G.M.; Kumar, M.; Gupta, J.K.; Sharma, L.D.; Dhar, G.M. Effect of Zr-SBA-15 support on catalytic functionalities of Mo, CoMo, NiMo hydrotreating catalysts. Catal. Today 2008, 130, 302-308. [CrossRef]

39. Li, F.; Yu, F.; Li, Y.; Li, R.; Xie, K. Direct synthesis of Zr-SBA-15 mesoporous molecular sieves with high zirconium loading: Characterization and catalytic performance after sulfated. Microporous Mesoporous Mater. 2007, 101, 250-255.

40. van Grieken, R.; Escola, J.M.; Moreno, J.; Rodríguez, R. Direct synthesis of mesoporous M-SBA-15 (M=Al, Fe, B, Cr) and application to 1-hexene oligomerization. Chem. Eng. J. 2009, 155, 442-450. [CrossRef]

41. Chen, S.-Y.; Lee, J.-F.; Cheng, S. Pinacol-type rearrangement catalyzed by Zr-incorporated SBA-15. J. Catal. 2010, 270, 196-205. [CrossRef]

42. Biswas, P.; Narayanasarma, P.; Kotikalapudi, C.M.; Dalai, A.K.; Adjaye, J. Characterization and activity of $\mathrm{ZrO}_{2}$ doped SBA-15 supported NiMo catalysts for HDS and HDN of bitumen derived heavy gas oil. Ind. Eng. Chem. Res. 2011, 50, 7882-7895. [CrossRef]

43. Iglesias, J.; Melero, J.A.; Bautista, L.F.; Morales, G.; Sánchez-Vázquez, R.; Andreola, M.T.; Lizarraga-Fernández, A. Zr-SBA-15 as an efficient acid catalyst for FAME production from crude palm oil. Catal. Today 2011, 167, 46-55. [CrossRef]

44. Vinu, A.; Murugesan, V.; Böhlmann, W.; Hartmann, M. An optimized procedure for the synthesis of AlSBA-15 with large pore diameter and high aluminum content. J. Phys. Chem. B 2004, 108, 11496-11505. [CrossRef]

45. Rodríguez-Castellón, E.; Jiménez-López, A.; Maireles-Torres, P.; Jones, D.J.; Rozière, J.; Trombetta, M.; Busca, G.; Lenarda, M.; Storaro, L. Textural and structural properties and surface acidity characterization of mesoporous silica-zirconia molecular sieves. J. Solid State Chem. 2003, 175, 159-169. [CrossRef]

46. Yang, L.; Yang, X.; Tian, E.; Vattipalli, V.; Fan, W.; Lin, H. Mechanistic insights into the production of methyl lactate by catalytic conversion of carbohydrates on mesoporous Zr-SBA-15. J. Catal. 2016, 333, 207-216. [CrossRef]

47. Handjani, S.; Marceau, E.; Blanchard, J.; Krafft, J.M.; Che, M.; Maki-Arvela, P.; Kumar, N.; Warna, J.; Murzin, D.Y. Influence of the support composition and acidity on the catalytic properties of mesoporous SBA-15, Al-SBA-15, and $\mathrm{Al}_{2} \mathrm{O}_{3}$-supported Pt catalysts for cinnamaldehyde hydrogenation. J. Catal. 2011, 282, 228-236. [CrossRef]

48. Zuo, H.; Liu, Q.; Wang, T.; Ma, L.; Zhang, Q.; Zhang, Q. Hydrodeoxygenation of methyl palmitate over supported Ni catalysts for diesel-like fuel production. Energy Fuels 2012, 26, 3747-3755. [CrossRef]

49. Han, J.X.; Sun, H.; Duan, J.Z.; Ding, Y.Q.; Lou, H.; Zheng, X.M. Palladium-catalyzed transformation of renewable oils into diesel components. Adv. Synth. Catal. 2010, 352, 1805-1809. [CrossRef]

50. Forzatti, P.; Lietti, L. Catalyst deactivation. Catal. Today 1999, 52, 165-181. [CrossRef] 
51. Kubička, D.; Kaluža, L. Deoxygenation of vegetable oils over sulfide Ni, Mo and NiMo catalysts. Appl. Catal. A Gen. 2010, 372, 199-208. [CrossRef]

52. Veriansyah, B.; Han, J.Y.; Kim, S.K.; Hong, S.; Kim, Y.J.; Lim, J.S.; Shu, Y.; Oh, S.; Kim, J. Production of renewable diesel by hydroprocessing of soybean oil: Effect of catalysts. Fuel 2012, 94, 578-585. [CrossRef]

53. Donnis, B.; Egeberg, R.G.; Blom, P.; Knudsen, K.G. Hydroprocessing of bio-oils and oxygenates to hydrocarbons. Understanding the reaction routes. Top. Catal. 2009, 52, 229-240. [CrossRef]

54. Yang, Y.; Ochoa-Hernández, C.; Pizarro, P.; de la Peña O'Shea, V.A.; Coronado, J.M.; Serrano, D.P. Synthesis of nickel phosphide nanorods as catalyst for the hydrotreating of methyl oleate. Top. Catal. 2012, 55, 991-998. [CrossRef]

(C) 2020 by the authors. Licensee MDPI, Basel, Switzerland. This article is an open access article distributed under the terms and conditions of the Creative Commons Attribution (CC BY) license (http://creativecommons.org/licenses/by/4.0/). 